\title{
ARGON ARC WELDING OF TITANIUM VT22 ALLOY USING FILLER FLUX-CORED WIRE
}

\author{
V.P. PRILUTSKY, S.L. SHVAB, I.K. PETRICHENKO, \\ S.V. AKHONIN, S.B. RUKHANSKY and I.A. RADKEVICH \\ E.O. Paton Electric Welding Institute, NASU \\ 11 Kazimir Malevich Str., 03680, Kiev, Ukraine. E-mail: office@paton.kiev.ua
}

\begin{abstract}
At the present time the use of welded assemblies and structures of high-strength titanium alloys $\left(\sigma_{t} \geq 1100 \mathrm{MPa}\right)$ is widened. Moreover, the strength characteristics of welded joints should be at the level of characteristics of alloys. For load-carrying elements of aircrafts of AN type, high-strength two-phase $(\alpha+\beta)$-titanium VT22 alloy is used. The aim of the work was the investigation of the influence of reducing the degree of weld metal alloying on its strength characteristics. For this purpose a completely new filler material, namely titanium flux-cored wire, for argon arc welding of VT22 alloy was developed. Despite the decrease in the degree of alloying of weld metal, its strength reaches 1121.5 MPa after the standard heat treatment, which is higher than the level of strength of the base metal (1057.5 MPa). Moreover, the impact toughness amounts to $70-75 \%$ of the base metal impact toughness. 15 Ref., 4 Tables, 6 Figures.
\end{abstract}

Keywords : titanium, welding, flux-cored wire, controlled magnetic field

One of the main technological processes in the manufacture of assemblies of aircraft engineering is welding. Weldability is an important factor determining the use of titanium alloys in the assemblies of aircraft engineering. In aircraft construction the low-alloyed titanium alloys, which are well-welded, became the most widely spread. In the operating conditions the characteristics of welded joints of these alloys are close to the corresponding characteristics of the alloys themselves. At the present time a considerable attention is paid to widening the use of welded structures and assemblies of high-strength titanium alloys with tensile strength of more than $1100 \mathrm{MPa}$.

The problem is put in the way that the mechanical characteristics of welded joints were close to the characteristics of alloys. It is connected with the appearance of such aircrafts as AN-124, AN-225, AN-70, AN-140, AN-148 and with the need to use the large-sized heavily loaded assemblies in their designs. They include chassis, frame rings, monorails, traverse beams, wing carriages and others. However, the weldability of the existing high-strength titanium alloys is significantly worse than that of the low-alloyed alloys. For load-carrying elements of aircrafts of the AN type the two-phase high-strength titanium alloy VT22 (system Ti-5Al-5Mo-5V-1Fe-1Cr) is widely used. It is applied both in annealed as well as in heat-hardened state.

The structure of annealed VT22 alloy consists of approximately equal amounts of $\alpha$ - and $\beta$-phases and, therefore, it belongs to the highest-strength titanium alloys in the annealed state. This property allows using VT22 alloy in the large-sized products, when the hardening heat treatment is complicated. An advantage of VT22 alloy as compared to other titanium alloys is the possibility of hardening by multi-stage annealing at the regulated cooling rate. However, its structure and properties depend much on the variation of chemical composition in the ranges established by GOST 19807-91.

This factor affects also weldability, and as far as according to the degree of alloying VT22 alloy belongs to the alloys with a critical composition, then under the influence of thermal cycle of welding the phase composition and the structure are formed in the weld metal and HAZ, having a very low ductility and impact toughness. Thus, during manufacture of welded structures of VT22 alloy using EBW the chemical composition of welds remains the same as that of the base metal, having a low ductility and impact toughness $[1,2]$. When the postweld hardening heat treatment of welded joint is applied according to the modes recommended for the base metals, the ever further reduction in mechanical properties of weld metal is observed. It greatly reduces the efficiency of EBW.

For the manufacture of welded titanium structures such a universal method became rather widely applied as argon arc welding using tungsten electrode (TIG) with surface arc. This method allows applying filler wire in welding into a groove, which makes it possible to change the composition of weld metal and also to adjust the thermal cycle of welding. In onepass arc welding of VT22 alloy the chemical composition remains the same as that of the base metal, 
the weld metal has also a low ductility and impact toughness. This is connected with the heterogeneity of the structure of different areas of the joint, arising under the influence of thermal cycle of welding and, as a result, with uneven distribution, shape and sizes of the decay products of $\beta$-solid solution [3]. It is assumed that a certain role here belongs to the chemical heterogeneity arising in the process of weld formation [4]. Therefore, while selecting the modes of heat treatment of welded joints of this alloy the phase and structural peculiarities should be considered, occurring after welding.

According to the prevailing assumptions, during welding of thermally hardened alloys to decrease the forming microheterogeneity of weld metal it is recommended to reduce the degree, as well as the system of its alloying by applying filler wires with different content of elements of $\beta$-stabilizers $[2,4-6]$. It helps improving the ductility of welds, but at the same time it greatly reduces their strength. Moreover, such a characteristic lack of thermally hardened twophase alloys is revealed as the decrease in ratio of weld strength to the strength of base metal during its hardening. Therefore it is recommended to locate the welds in the thickened areas.

Till now this technique is considered as the only possibility to realize the strength characteristics in welded structures of VT22 alloy [4]. At the present time in accordance with these preconditions, high-alloyed welding wire of SP15 grade (Ti-4.5Al-2V$3 \mathrm{Mo}-3.5 \mathrm{Nb}-1.5 \mathrm{Zr}$ ) with tensile strength of not lower than $750 \mathrm{MPa}$ became widely applied [5, 7]. The total equivalent by molybdenum of this wire reaches $7.5 \%$ and, therefore, it is recommend for application in welding of two-phase titanium alloys of a large range. The tensile strength of welds of VT22 alloy, made by this wire, does not exceed $1000 \mathrm{MPa}$.

It should be noted that the process of manufacturing of high-alloyed filler wire is characterized by a technological complexity and high power consumption (after each $0.15 \mathrm{~mm}$ transition an etching in acids and vacuum annealing should be carried out). In addition, the composition of SP15 wire includes a number of expensive and scarce elements such as $\mathrm{V}, \mathrm{Mo}, \mathrm{Nb}$ and Zr. After completion of the process of manufacturing wire, some small defects still remain on its surface in the form of tears, microcracks, remnants of oxide layers. The depth of occurrence of such defects is regulated and in accordance with GOST 27265-87 it is not more than $0.4 \mathrm{~mm}$. In welding they can be a source of additional contamination of weld metal with interstitial impurities and also they contribute to appearance of porosity in them. The presence of porosity results in a loss of service characteristics of products, reduction of mechanical properties, static and especially fatigue strength of welded joints $[8,9]$. In TIG it is possible to prevent the occurrence of such defects by using the metallurgical treatment of a weld pool with a liquid flux when it is introduced into the arc zone, thus increasing the cyclic strength of welded joints [10].

In TIG welding with edge preparation the mixing of filler and base metals occurs, as a result of which the chemical and phase composition of the weld differs both from the composition of base metal as well as from the composition of the filler wire. As a consequence, the resulting structural and chemical heterogeneity leads to anisotropy of physical and mechanical properties, and the difference in phase composition of the HAZ and the weld requires a careful selection of modes of heat treatment of welded assemblies.

The basic aim of the work was investigation of the effect of reducing the degree of the weld metal alloying without changing the composition of alloying elements on the formation of the required phase composition and the structure of weld metal and the strength characteristics during application of heat treatment of welded joint. The task of the investigations included the search for conditions and parameters of welding process, under which the chemical and physical heterogeneity developed in the layers of the deposited metal and HAZ would be minimal. Solution of this problem can significantly simplify the process of heat treatment of welded joints and obtain the desired complex of mechanical characteristics.

As far as VT22 alloy has a high sensitivity to a thermal cycle of welding, first of all, it is necessary to create such conditions of weld formation, under which it is possible to adjust the parameters of thermal cycle in order to reduce the length of HAZ. This, in its turn, will affect intragranular structure and phase composition of the weld and HAZ metal properties. For this purpose, to control the process of weld formation, the external transverse magnetic field was applied, the application of which was realized during automatic narrow-gap welding of titanium [11] and in manual welding under the site conditions [12]. It allowed controlling the spatial position of arc column and redistributing its thermal energy between the base metal, filler wire and weld metal.

The mechanical characteristics of the weld metal during welding with edge preparation can be changed by choosing an appropriate thermal cycle of welding and the mode of subsequent heat treatment of welded joint, as well as by controlling the degree of weld metal alloying. For this purpose, on the basis of previous investigations a principally new filler material was developed for welding titanium, namely titanium 
Table 1. Content of alloying elements in the granules of VT22 alloy (results of spectral analysis)

\begin{tabular}{|c|c|c|c|c|c|c|c|c|}
\hline \multirow{2}{*}{ Components } & \multicolumn{9}{|c|}{ Chemical composition, wt.\% } \\
\cline { 2 - 10 } & $\mathrm{Al}$ & $\mathrm{V}$ & $\mathrm{Mo}$ & $\mathrm{Zr}$ & $\mathrm{Si}$ & $\mathrm{Fe}$ & $\mathrm{Cr}$ & $\mathrm{Ti}$ \\
\hline GOST 19807-91 & $4.4-5.7$ & $4.0-5.5$ & $4.0-5.5$ & 0.3 & 0.15 & $0.5-1.5$ & $0.5-1.5$ & $\mathrm{Rest}$ \\
\hline Granules & 5.6 & 4.8 & 5.0 & 0.05 & 0.12 & 0.72 & 1.0 & Rest \\
\hline
\end{tabular}
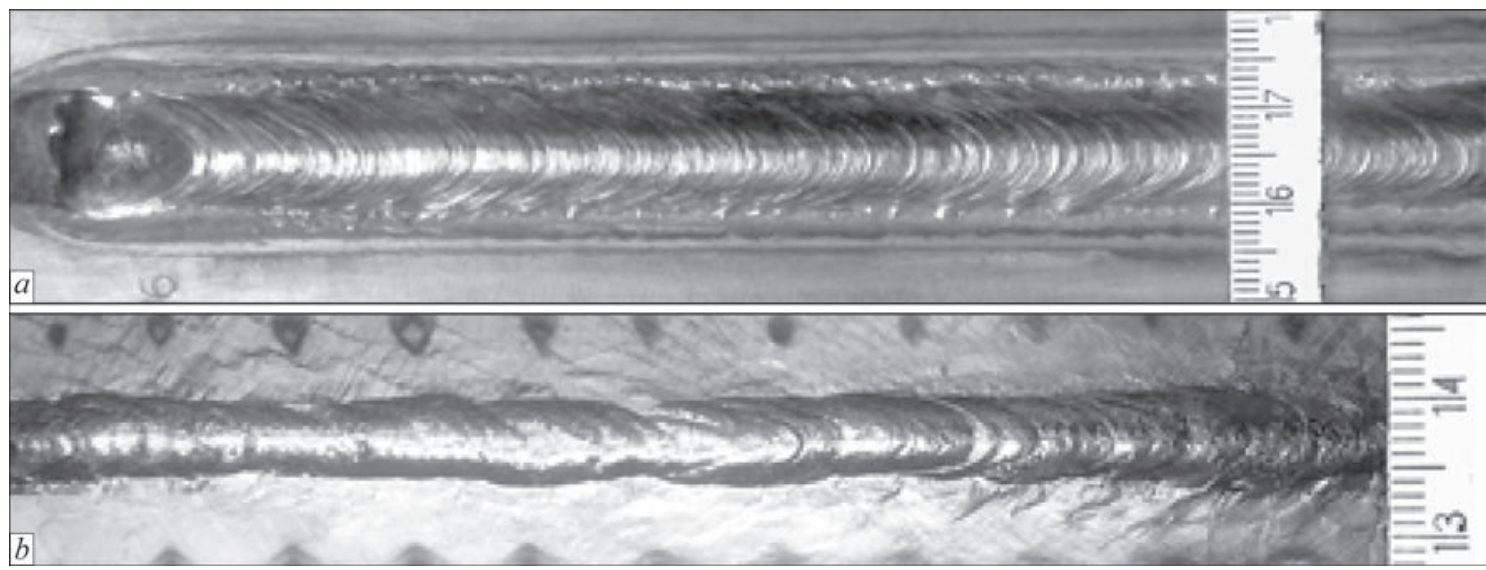

Figure 1. Specimen of welded joint of VT22 alloy $8 \mathrm{~mm}$ thick produced using filler flux-cored wire PPT-22: $a$ - face weld surface; $b$ - reverse formation

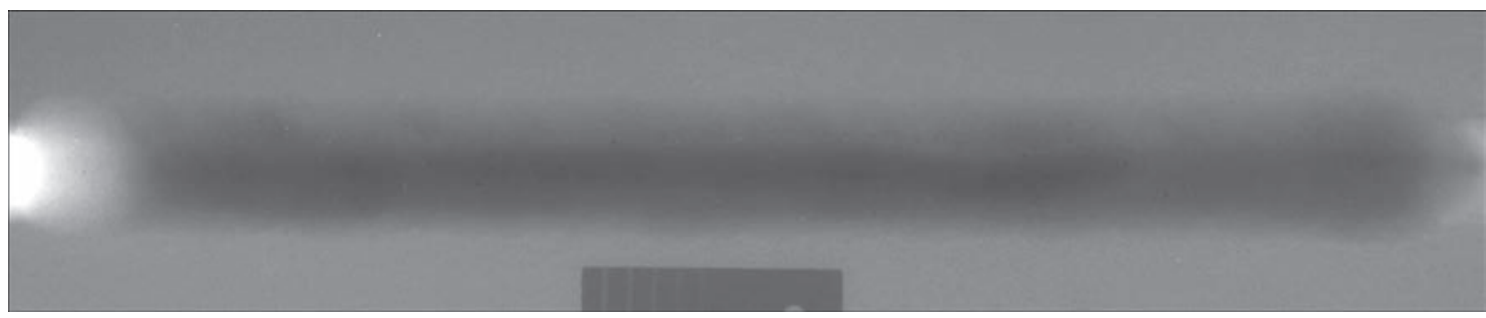

Figure 2. Radiogram of welded joint produced using filler flux-cored wire PPT-22

filler flux-cored wire $[13,14]$. It represents a tubular sheath of commercial titanium of grade VT1-00, inside which there is the core composed of metal and flux components. Such a design unlike the solid wire allows introducing a flux component into the core intended to prevent the occurrence of porosity in welds and the arc constriction. The flux component of the core includes fluorides of alkaline earth metals.

As the metal component it was suggested to use granules produced by plasma centrifugal spraying from the billet of VT22 alloy (Table 1).

The experiments on the development of welding technology were carried out on the specimens of VT22 alloy of $8 \mathrm{~mm}$ thickness with V-shaped preparation at $90^{\circ}$ angle of edges opening and at $1 \mathrm{~mm}$ rootface. As the filler material the experimental flux-cored wire PPT-22 of $3 \mathrm{~mm}$ diameter was used. In welding an external transverse alternating magnetic field (the frequency is $20 \mathrm{~Hz}$, magnitude of magnetic induction is $4 \mathrm{mT}$ ) was used to move the arc column and, accordingly, the weld pool across the weld. The welding modes are given in Table 2, the appearance of welded specimen is shown in Figure 1. Figure 2 shows the radiogram of welded joint, confirming that the use of flux component in the flux-cored wire prevents the arising of pores in the weld.

The macrosection of the produced joint is shown in Figure 3. The comparison of microstructures of weld metal, produced during welding with magnetic control and without it, shows that the use of an alternating magnetic field allows adjusting not only the sizes of the weld, but also influencing the crystallization conditions of the weld pool metal by promoting the formation of a more uniform and homogeneous structure. Thus, in welding without application of magnetic field the intragranular structure is heterogeneous, the areas with intensive decay and high density of plate martensite particles are observed in it, which are alternated with the light areas, where the density of martensite particles is smaller, i.e. the decay of $\beta$-solid solution is not uniform (Figure $4, a$ ). Under the influence of alternating magnetic field on the metal of the weld pool a large uniformity of decay of solid

Table 2. Parameters of the mode for welding specimens

\begin{tabular}{|c|c|c|c|c|}
\hline \multirow{2}{*}{$\begin{array}{c}\text { Number } \\
\text { of pass }\end{array}$} & \multicolumn{4}{|c|}{ Welding parameters } \\
\cline { 2 - 5 } & $I_{\mathrm{w}}, \mathrm{A}$ & $U_{\mathrm{a}}, \mathrm{V}$ & $v_{\mathrm{w}}, \mathrm{m} / \mathrm{h}$ & $v_{\text {feed }}, \mathrm{m} / \mathrm{h}$ \\
\hline 1 & 200 & 13.0 & 9 & 30 \\
\hline 2,3 & 220 & 13.5 & 7 & 30 \\
\hline
\end{tabular}


Table 3. Mechanical properties of as-welded weld metal of VT22 alloy with thickness of $8 \mathrm{~mm}$

\begin{tabular}{|c|c|c|c|c|c|}
\hline \multirow{2}{*}{$\begin{array}{c}\text { Sampling } \\
\text { of test specimens }\end{array}$} & \multicolumn{5}{|c|}{ Mechanical properties } \\
\cline { 2 - 6 } & $\sigma_{\mathrm{y}}, \mathrm{MPa}$ & $\sigma_{\mathrm{t}}, \mathrm{MPa}$ & $\delta, \%$ & $\psi$ & $\mathrm{K}, \%, \mathrm{~J} / \mathrm{cm}^{2}$ \\
\hline Base metal & 1003.8 & 1039.7 & 9.6 & 23.5 & 32.6 \\
\hline Weld metal & 987.7 & 1065.1 & 9.0 & 23.9 & 5.9 \\
\hline
\end{tabular}

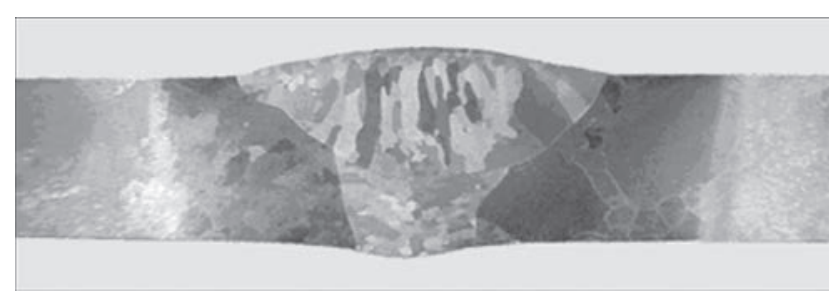

Figure 3. Macrosection of welded joint of VT22 alloy $8 \mathrm{~mm}$ thick in the as-welded state

solution and formation of a more homogeneous structure (Figure $4, b$ ) is achieved.

The results of mechanical tests of the weld metal in the as-welded state are given in Table 3.

The obtained results show that the use of magnetic field had no effect on the value of impact toughness of the weld metal in the as-welded state.

As a rule, the welded joints after welding are subjected to annealing. An effective way to improve the ductile properties of VT22 alloy is a high-temperature annealing in the two-phase area at the temperature range of $750-800{ }^{\circ} \mathrm{C}$ followed by the furnace cooling [15]. The purpose of annealing is not only to eliminate thermal welding stresses, but also to obtain a uniform

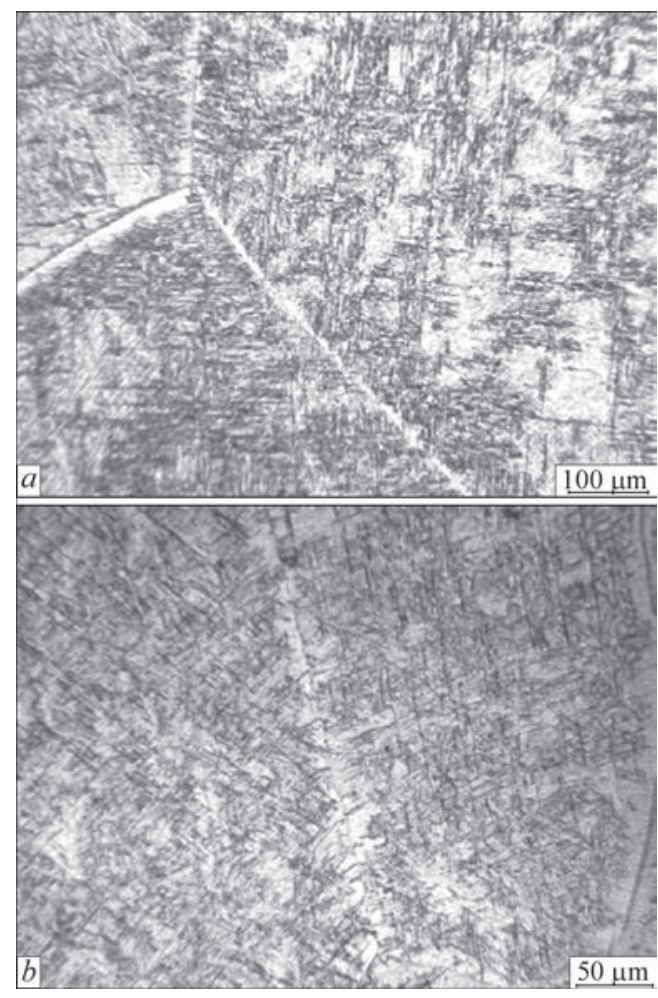

Figure 4. Microstructure of weld metal of welded joint of VT22 alloy $8 \mathrm{~mm}$ thick: $a$ - without; $b$ - with the use of magnetic field
Table 4. Mechanical properties of welded joint and base metal in the state after heat treatment

\begin{tabular}{|l|c|c|c|c|c|}
\hline \multicolumn{1}{|c|}{ Metal } & $\begin{array}{c}\sigma_{\mathrm{y}^{\prime}} \\
\mathrm{MPa}\end{array}$ & $\begin{array}{c}\sigma_{\mathfrak{t}^{\prime}} \\
\mathrm{MPa}\end{array}$ & $\begin{array}{c}\delta, \\
\%\end{array}$ & $\begin{array}{c}\psi, \\
\%\end{array}$ & $\begin{array}{c}K C V, \\
\mathrm{~J} / \mathrm{cm}^{2}\end{array}$ \\
\hline Welded joint & - & $1121.5^{*}$ & - & - & 14.8 \\
\hline Base metal & 974.1 & 1057.5 & 13.3 & 33.3 & 19.6 \\
\hline
\end{tabular}

equilibrium structure with a desired ratio of $\alpha$ - and $\beta$-phases. Based on the analysis of literature data and recommendations of the authors of [15], a rather simple technology of heat treatment process was chosen for welded joints produced using a filler flux-cored wire, namely soaking in the furnace at $T=750{ }^{\circ} \mathrm{C}$ during $1 \mathrm{~h}$, cooling in the furnace.

The results of mechanical tests of welded joint and base metal in the as-treated state are given in Table 4.

The macrosection of welded joint after heat treatment is shown in Figure 5.

The investigations of microstructure of welded joints after annealing showed that in HAZ a rather uniform metastable decay of $\beta$-phase is observed with precipitation of dispersed particles of martensite $\alpha^{\prime} / \alpha^{\prime \prime}$-phase, the subgrain structure retained and the partial recrystallization of $\beta$-grain occurred (Figure 6, $b$ ). Along the boundaries of large $\beta$-grains the small recrystallized grains were formed.

The annealing contributed to the formation of a homogeneous and uniform metal structure in the weld height (Figure 6,c), at the same time a decay of metastable phases also occurred, however, the weld sizes of the decay products are larger than in the HAZ, that is associated with some disalloying of weld metal due to the sheath of flux-cored wire.

Thus, it can be concluded that the use of metal granules of VT22 alloy as the metallic component of the core of flux-cored wire in combination with the controlled magnetic field has a positive effect on the

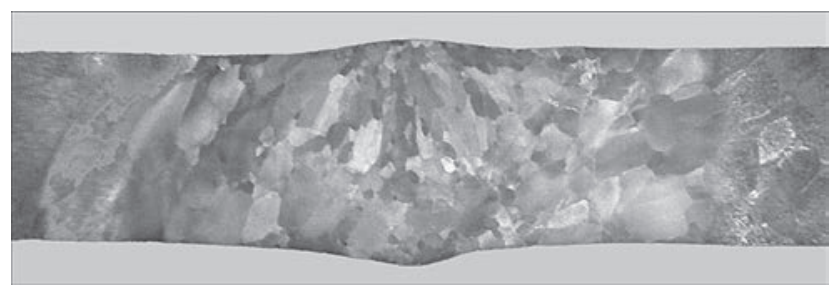

Figure 5. Macrosection of welded joint of VT22 alloy $8 \mathrm{~mm}$ thick in the as-treated state 


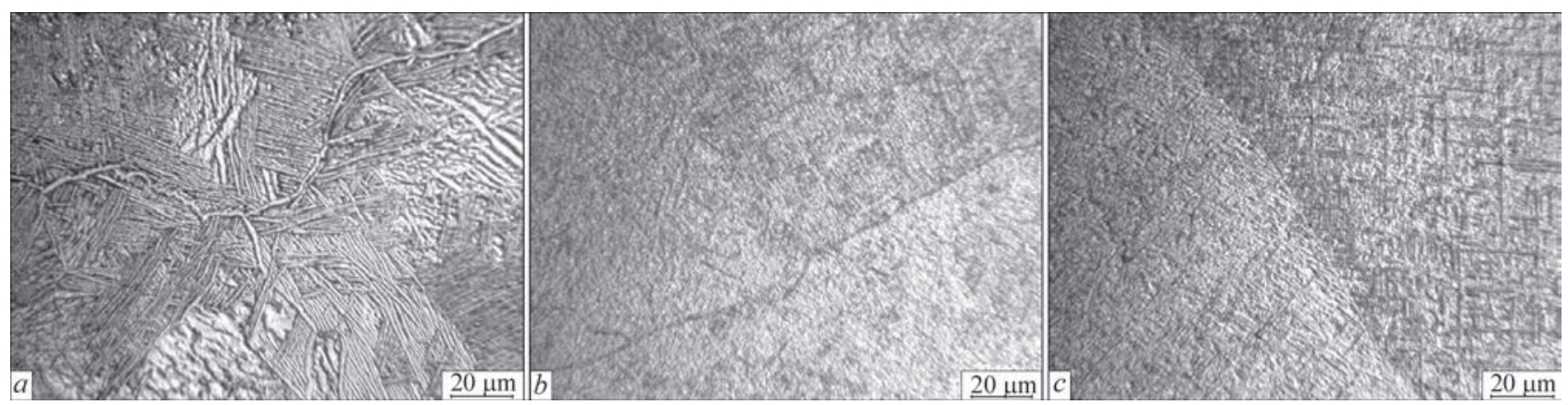

Figure 6. Macrostructure of welded joint after heat treatment: $a-\mathrm{BM} ; b-\mathrm{HAZ} ; c-$ weld

properties of welded joint at the selected mode of heat treatment. The strength of weld metal is achieved being higher than the level of the base metal strength, despite the reduction in the degree of weld alloying. Here the impact toughness amounts to $70-75 \%$ of the base metal impact toughness.

1. Zamkov, V.N., Shevelev, A.D., Arsenyuk, V.V. et al. (1984) Improvement of EBW technology of VT22 titanium alloy. Avtomatich. Svarka, 1, 56-58.

2. Moiseev, V.N., Kulikov, F.R., Kirilov, Yu.G. et al. (1975) Welded joints of titanium alloys. Moscow: Metallurgiya.

3. Notkin, A.B., Korobov, O.S., Pertsovsky, N.Z. et al. (1982) Influence of initial structure on mode of $\beta$-solid solution in high-strength titanium alloy VT22. Fizika Metallov i Metallovedenie, 54(Issue 4), 755-761.

4. Gurevich, S.M., Kulikov, F.R., Zamkov, V.N. et al. (1975) Welding of high-strength titanium alloys. Moscow: Mashinostroenie.

5. Gurevich, S.M., Zamkov, V.N., Kushnirenko, N.A. et al. (1980) Selection of filler material for welding of $(\alpha+\beta)$-titanium alloys. In: Actual problems of welding of non-ferrous metals, 314-320. Kiev: Naukova Dumka.

6. Glazunov, S.G., Gruzdeva, L.F., Moiseev, V.N. et al. Filler material for welding of titanium alloys with higher $\beta$-phase content. USSR author's cert. 1662217. Publ. 1964.
7. GOST 27265-87: Technical specifications. Welding wire from titanium and titanium alloys.

8. Kulikov, F.R., Vaskin, Yu.V., Kishkina, S.I. et al. (1977) Influence of technological factors on low-cycle fatigue of VT22 alloy welded joints. Aviats. Promyshlennost, 6, 65-71.

9. (1978) Low-cycle fatigue of welded joints of $(\alpha+\beta)$-titanium alloys. In: Proc. of $3^{\text {rd }}$ Int. Conf. on Titanium, Vol. 2, 273-281. Moscow: VILS.

10. Gurevich, S.M., Zamkov, V.N., Blashchuk, V.E. et al. (1986) Metallurgy and technology of welding of titanium and its alloys, 128. Kiev: Naukova Dumka.

11. Paton, B.E., Zamkov, V.N., Prilutsky, V.P. (1996) Narrow-groove welding proves its worth on thick titanium. Welding $J ., 5$.

12. Zamkov, V.N., Prilutsky, V.P. (2005) Methods for welding titanium alloys. The Paton Welding J., 8, 41-44.

13. Gurevich, S.M., Zamkov, V.N., Prilutsky, V.P. Flux-cored welding wire. Pat. 4131493 US. Publ. 1978.

14. Prilutsky, V.P., Zamkov, V.N., Radkevich, I.A. et al. Filler material based on titanium alloy. Pat. 25333 Ukraine. Int. Cl. B23K 35/36. Fill. 08.05.1997. Publ. 30.10.1998.

15. Anisimova, L.I., Popov, A.A., Melnikova, V.I. et al. (1977) Effect of heat treatment on structure and properties of VT22 titanium alloy. Fizika Metallov i Metallovedenie, 44(Issue 4), 843-845. 